\title{
UIVIA NOVA PROPOSTA PARA O ESTÁGIO DE PRATICA DE ENSINO EM PSICOLOGIA
}

\author{
MARY NEIDE DAMICO FIGUEIRÓa
}

\section{RESUMO}

O objetivo do presente trabalho foi propor uma nova alternativa para os estágios de Prática de Ensino em Psicologia que aprimorasse as experiências do licenciando no campo da Educação, dando mais qualidade a esses estágios, num vínculo com as necessidades da comunidade. A metodologia consistiu no planejamento, execução e avaliação de cursos-evento-extensão de 20 ou 30 horas pelos licenciandos junto a alunos de $1^{\circ}$ e $2^{\circ}$ graus, professores de pré-escola e $1^{\circ}$ grau, funcionários de creche $e$ comunidade em geral. Quanto aos resultados, os licenciandos avaliaram, numa proporçao significativamente maior, como sendo ótima a experiência em Prática de Ensino e a contribuição do estágio para a sua vida profissional. A clientela, em sua totalidade, avaliou de forma positiva a qualidade dos cursos e o alcance dos objetivos propostos. Conclui-se que esta nova alternativa trouxe aprimoramento ao estágio de Licenciatura, favoreceu a integração do $3^{\circ}$ grau com o ensino de $1^{\circ}$ e $2^{\circ}$ graus e comunidade em geral, priorizando a democratizaçao do saber.

PALAVRAS-CHAVE: Licenciatura em Psicologia; Prática de Ensino; Estágio de Psicologia; Cursos-evento-extensão

\section{1 - INTRODUÇÃO}

É necessário que se. reflita sobre como vem sendo desenvolvidos e ao mesmo tempo considerados os cursos de Licenciatura nas Universidades.

De acordo com Carvalho e Vianna (1), em todos os cursos de graduação se prioriza o bacharelado e a pós-graduação, em detrimento da Licenciatura, gerando assim uma desconexão entre os objetivos: formar professores e pesquisadores.

Este ponto precisa ser considerado quando se discute, inclusive, a problemática da formação do professor de $1^{\circ}$ grau, pois, como salienta Gatti (2): um dos grandes fatores responsáveis pela má formação deste profissional é a deficiéncia das licenciaturas, especialmente do curso de Pedagogia.

É preciso pois um repensar constante sobre os objetivos das Práticas de Ensino e suas influências no ensino de $1^{\circ}$ e $2^{\circ}$ graus.

Além disto, faz-se necessária uma avaliação continuada de todo esse processo.

Vários autores se dispõem a fazer uma análise crítica da Licenciatura, entre eles: Mello, Maia e Britto (3), Boyteux (4), Gatti (2), Balzan e Paoli (5) e Braga (6).

"As Práticas de Ensino devem proporcionar o caráter abrangente da formação do educador, englobando a adequação, dosagem, organização e aplicação do conhecimento a ser lecionado nos diversos graus de ensino nas diferentes realidades existentes", (Carvalho e Vianna (1)).

Balzan e Paoli ${ }^{(5)}$ discutem o descaso das políticas go- vernamentais que vêm causando uma constante deteriorização das condições de trabalho e de existência dos professores e afirmam que o aviltamento da profissão não deve servir de desculpa para a falta de cuidado com a qualidade do ensino desses profissionais.

Discutir a questão das Licenciaturas é discutir portanto a formação de profissionais da educação, atentando para a importância desta para o crescimento do país.

Preocupados com a reflexão sobre a Licenciatura, Educadores da Universidade Estadual de Londrina promoveram no ano de 1989 o $1^{\circ}$ Ciclo de Debates sobre as Licenciaturas desta Instituição, onde participaram docentes responsáveis pela Prática de Ensino de cada Departamento.

Este evento, que embora não tenha tido continuidade, foi útil no sentido de propiciar uma reflexão conjunta sobre a necessidade da busca de novas alternativas em Prática de Ensino.

É necessário que educadores das diversas Instituições de Ensino Superior do país estejam unindo esforços no sentido de tentar integrar suas idéias, procurando analisar e reformular as Licenciaturas na busca de soluções conjuntas.

Parra ${ }^{(7)}$ preocupado com currículo para licenciatura propõe uma abordagem diferente para a composição dos cursos de licenciatura, onde problemas reais do ensino brasileiro deveriam constituir os temas básicos geradores e as mais diversas disciplinas acadêmicas seriam solicitadas a contribuir.

No Curso de Psicologia, a Prática de Ensino deve ser um momento que possibilite ao licenciando a experiencia como professor de Psicologia, seja no $2^{\circ}$ grau, ou em con- 
textos onde se justifiquem a necessidade desses conteúdos.

A Coordenadoria de Estudos e Normas Pedagógicas, o CRP - $6^{a}$ região e o Sindicato de Psicólogos do Estado de São Paulo $\left.{ }^{8}\right)$ destacaram a relevância da Filosofia, Sociọlogia e Psicologia para a educação geral do aluno de $2^{\circ}$ grau.

"A disciplina Psicologia pode contribuir no sentido de oferecer elementos que auxiliem o Homem a analisar as suas relações com o Mundo, ou seja, identificar e discutir fatores mediatos e imediatos que determinam ou interferem no seu comportamento, entendido aqui numa visão ampla, abrangendo tanto eventos externos como os eventos internos" (Comissão de Ensino CRP - Sindicato ${ }^{9}$ ).

Considerando a baixa qualidade dos cursos de Magistério apontada por Mello, Maia e Britto (3), Gatti (2) e Mezzaroba $(10)$, entre outros, bem como a pequena carga horária total das disciplinas de Psicologia nesse curso, acredita-se que o oferecimento de cursos de extensão para estudantes desse nível de ensino possa vir a contribuir para a formação profissional destes.

A necessidade e utilidade de uma complementação para os cursos de $2^{\circ}$ grau não se restringe a alunos dos magistério, e além das disciplinas de Psicologia do Desenvolvimento e da Aprendizagem, também a disciplina Psicologia do Inter-relacionamento Humano parece ser de grande importância para a otimização dos recursos humanos.

Tendo em vista a relevância das contribuições que a Psicologia - enquanto ensino de disciplinas básicas - pode oferecer ao "Homem", torna-se necessário que estes benefícios sejam ampliados para outros contextos, a fim de atingir outras pessoas além do aluno de $2^{\circ}$ grau, como por exemplo: professores, crianças e adolescentes.

Boyteux ${ }^{(4)}$ ao falar sobre a valorização do profissional do magistério, diz que devem ser organizados cursos para o maior número possível de professores de $1^{\circ} \mathrm{grau}$.

Cetani ${ }^{(11)}$ propõe que quando se planejam cursos para professores, os mesmos sejam organizados de tal forma que permitam desenvolver a "educação continuada" do professor, onde se considera a continuidade, a integração de diferentes níveis de participação e responsabilidade, e, particularmente, mudanças de atitudes, hábitos e crenças como elementos fundamentais.

No que diz respeito à extensão dos conteúdos de Psicologia à crianças e adolescentes, Campos $(12)$ afirma que são poucas as orientações a educadores no sentido de auxiliá-los a transmitir informações e conteúdos de psicologia à população dessa faixa etária. Critica o fato de os cursos e programa de psicologia visarem somente o adulto. Em seu texto, a autora faz uma análise de como as crianças e adultos poderiam se beneficiar com esses conhecimentos.

Isto tem a ver com a democratização do saber, seriamente defendida por Gnerre (13) e vários outros educadores.

Retomando as reflexões sobre a Licenciatura, supõese que ela própria possa vir a integrar os já citados objetivos da graduação, quais sejam: formar professores e pesquisadores.

Ao falar sobre procedimentos metodológicos, Ronca e Escobar (14) afirmam que a "prática na sala de aula" é muito importante na busca dos esclarecimentos.

168
Sumarizando, professores, pedagogos e psicólogos que desejam fazer de sua ação educativa um processo libertador, precisam, como ponto de partida para sua desafiadora tare$\mathrm{fa}$, vivenciar o papel de professor.

O presente trabalho surgiu da preocupação dos docentes da área de Psicologia Escolar do Departamento de Psicologia Social e Institucional da UEL, com relação ao estágio de Licenciatura, onde o mesmo, seguindo tradicionalmente as etapas de Observação, Participação e Direção de Classe, era realizado apenas nas salas de aula do $2^{\circ}$ grau, seguindo programações pré-estabelecidas. Tal forma de trabalho vinha sendo desenvolvida sem qualquer inovação, desde que o curso de Psicologia foi implantado.

Relevantes justificativas nortearam a elaboração da referida proposta, a saber:

- a importância de se estruturar uma proposta de trabalho que atenda aos objetivos da disciplina "Metodologia e Prática do Ensino II", aprimore as experiências do licenciando no campo da Educação, dando mais qualidade aos estágios, num vínculo com as necessidades da comunidade;

- a avaliação feita com relação à forma "tradicional" (observação, prática e direção de classe) com que se vinha efetivando a Prática de Ensino, indicando que era pouco enriquecedora para o licenciando, ao mesmo tempo que não refletia em contribuições para a comunidade;

- a necessidade e utilidade da experiência, para o profissional da área de psicologia, em programar, ministrar e avaliar um curso, seja qual for sua área de atuação;

- o reconhecimento da importância dos conteúdos de Psicologia do Desenvolvimento, da Aprendizagem e do Inter-relacionamento Humano para a "educação geral" e para o aprimoramento da "formação" de alunos de $2^{\circ}$ grau, e da "competência profissional" de professores de pré e $1^{\circ} \mathrm{grau}$ e da comunidade em geral.

Em função disto, os principais objetivos gerais estabelecidos foram:

- contribuir para o aprimoramento do estágio de Prática de Ensino em Psicologia;

- inovar a ação pedagógica a partir de um vínculo com as exigências sócio-político-culturais;

- favorecer a integração do $3^{\circ}$ grau com o ensino de $1^{\circ}$ e $2^{\circ}$ graus e comunidade em geral;

- oportunizar a democratização do saber.

\section{2 - METODOLOGIA}

\subsection{Sujeitos}

- alunos estagiários do $8^{\circ}, 9^{\circ}$ ou $10^{\circ}$ períodos de Psicologia regularmente matriculados na disciplina Metodologia e Prática de Ensino em Psicologia;

- clientela: alunos de $1^{\circ}$ e $2^{\circ}$ grau, professores de pré e $1^{\circ} \mathrm{grau}$, funcionários de creche e comunidade em geral;

\subsection{Material}

O conjunto de materiais empregados consistiu em:

a. uma ficha padronizada de Avaliação Final para a Prática de Ensino em psicologia, que deveria ser preenchida 
pelo licenciando ao final deste seu estágio;

b. uma ficha padronizada de Avaliação da Educação Continuada dos Professores, que era aplicada no final do curso-evento-extensão, quando este era ministrado para professores de pré e $1^{\circ}$ grau.

\subsection{Procedimento}

Os licenciandos da disciplina Metodologia e Prática de Ensino em Psicologia II, organizados individualmente, ou em dupla, após receberem da supervisora as orientações para o estágio, davam início à etapa de levantamento de temas de interesse para cursos junto à comunidade. Cabia à supervisora contatuar anteriormente com as Instituições para, junto à direção destas, divulgar as propostas de cursos-evento-extensão e formalizar todo o acordo caso a mesma abrisse espaço para o trabalho.

Para definição final do tema do curso, os licenciandos geralmente precisavam contatuar mais de uma vez com a clientela. Tendo porém definido o tema, voltavam na Instituição para realizar as inscrições informais dos interessados e definir o período e horário para realização do curso.

Dando prosseguimento ao trabalho, os licenciandos passavam a se dedicar ao planejamento do programa, bem como ao preenchimento dos formulários (Evento de Exten. são: Proposta) da CEC (Coordenadoria de Extensão à Co munidade).

Estando aprovado o projeto de curso nas diferentes instâncias definidas pela CEC, os licenciandos efetivavam as inscrições e davam início ao curso.

A supervisora procurava acompanhar junto ao licenciando os quatro momentos do trabalho: diagnóstico (levantamento de necessidade para definição do tema do curso); planejamento (elaboração do programa do curso; indicação de material bibliográfico); execução (discussão dos resultados, passo a passo; discussão das dificuldades e da necessidade de modificações no decorrer do curso); avaliação (seleção de estratégias para verificação do conteúdo durante e ao final do curso; adequação da estratégia de avaliação ao tipo de clientela).

Ao final de cada curso, além da avaliação do conteúdo, era feita uma avaliação do curso como um todo, momento útil para críticas e sugestões. Na maioria das vezes esta avaliação era feita individualmente por escrito e muitas vezes também oralmente para que todo o grupo pudesse tomar conhecimento.

Quando a clientela era formada por professores de pré e de $1^{0}$ grau, cada elemento preenchia a ficha de Avaliaça da Educação continuada dos Professores. Esta ficha, composta de quinze itens, tinha duas finalidades: possibilitar que o professor avaliasse o curso do qual participou e manifestasse seu interesse ou não por continuar participando desses trabalhos, incluindo sugestões de temas para próximos cursos.

Um outro instrumento de avaliação, intitulado: "Avaliação Final da Disciplina" era preenchido individualmente pelos licenciados ao final de cada semestre letivo. Esta ficha, além de consistir em um espaço para auto-avaliação, críticas e sugestões à disciplina, permitia verificar, entre outros dados, como o licenciando avaliava sua experiência em ministrar curso e, em especial, como ele avaliava a contribuição deste trabalho para a sua formação profissional.

Esse instrumento foi elaborado (e iniciado a sua aplicação) no período em que a Prática de Ensino era realizada segundo a forma "tradicional", portanto anterior ao segun do semestre de 1989.

O trabalho de cada licenciando culminava finalmente na elaboração do relatório final segundo os moldes científicos.

Essa estratégia de trabalho foi desenvolvida em cará. ter experimental por dois semestres (1989/2 e 1990/1) sendo depois organizada em forma de Projeto de Ensino. Este projeto; oficialmente regulamentado, foi colocado em práti ca no segundo semestre de 1990 e primeiro de 1991.

\section{3 - RESUltAdOS}

Em termos da quantidade de cursos oferecidos para a comunidade, nos dois semestres experimentais foram ministrados 10 cursos, sendo 5 em cada semestre, enquanto que nos dois semestres seguintes, quando o Projeto de Ensino já estava oficializado, foram ministrados 17 cursos, sendo 9 no primeiro semestre e 8 no segundo.

Em dois anos portanto, foi possível efetivar a realização de 27 cursos evento-extensão. No que diz respeito à clientela envolvida, os mesmos foram distribuídos da seguinte forma: 8 cursos para professores de pré e $1^{\circ}$ grau; 1 para professor de $2^{\circ}$ grau; 15 para alunos de $1^{\circ}$ e $2^{\circ}$ grau e 3 para funcionários de creche.

Quanto aos temas, que eram definidos segundo a necessidade da clientela, 10 cursos foram de temas relacionados ao Desenvolvimento Humano, 11 à Psicologia do Interrelacionamento e 6 à Psicologia do Ensino-Aprendizagem. "

No que diz respeito às Instituições atendidas, obtevese a abertura para o estágio junto a um número suficiente de Instituições, com possibilidade de continuidade de trabaIho, conforme mostra o Quadro 1.

Analisando os dados do instrumento: Avaliação Final da Disciplina, preenchido pelo licenciando ao final do estágio, foi possível obter, selecionando algumas questões, os resultados demonstrados nos quadros 2 e 3.

Quanto ao instrumento de avaliação intitulado: "Avaliação da Educação Continuada dos Professores", os resultados de algumas questões selecionadas estão demonstradas nos quadros 4 e 5 . Nestes são registrados os dados referentes apenas aos períodos em que o Projeto já havia sido oficializado, devido ao fato desse instrumento ser criado juntamente com a elaboração-do Projeto.

Quando a clientela participante dos cursos foi composta por alunos de $2^{\mathrm{O}}$ grau ou pessoas da comunidade em geral, foi possível constatar - conforme avaliação por escrito incluída como anexo nos relatórios dos licenciandos que, nos diferentes semestres, a clientela avaliou positivamente os cursos e, na maioria das vezes, agradeceu o trabatho e ressaltou a importância do evento para seu enriquecimento. 
QUADRO 1 - QUADRO DEMONSTRATIVO DE INSTITUICCOES ONDE FOI MINISTRADO CURSO POR MAIS DE UM SEMESTRE

\begin{tabular}{|c|c|c|c|c|}
\hline & \multicolumn{2}{|c|}{$\begin{array}{l}\text { Período } \\
\text { Experimental }\end{array}$} & \multicolumn{2}{|c|}{$\begin{array}{l}\text { Período em que } \\
\text { já havia oficializa } \\
\text { ção do Projeto }\end{array}$} \\
\hline & $1989 / 2$ & $1990 / 1$ & $1990 / 2$ & $1991 / 1$ \\
\hline Colégio Mãe de Deus & & x & $\mathrm{x}$ & $x$ \\
\hline Colégio Maria do & & & & \\
\hline Rosário Castaldi & & $x$ & $x$ & \\
\hline \multicolumn{5}{|l|}{ Colégio José Al. } \\
\hline Aragão & & & $x$ & $x$ \\
\hline IEEL & & & $x$ & $x$ \\
\hline Rede Municipal de & & & & \\
\hline $\begin{array}{l}\text { Ibiporã. Departa- } \\
\text { mento de Educação }\end{array}$ & $x$ & $x$ & $x$ & $x$ \\
\hline \multicolumn{5}{|l|}{ Creche Arlete Vila } \\
\hline Richa & & $x$ & $x$ & \\
\hline
\end{tabular}

QUADRO 2 - RESULTADO DA QUESTÃO 1 DO INSTRUMENTO: "AVALIAÇÃO FINAL DA DISCIPLINA 1 EST 228"

Questão 1: De forma geral a sua experiência em Prática de Ensino em Psicologia pode ser considerada:

( ) ótima ( ) boa ( ) regular ( ) fraca

\begin{tabular}{lccc}
\hline & Ótima & Boa & Regular Fraca \\
\hline $1989 / 2$ (fase experimental) & $85 \%$ & $15 \%$ & \\
$1990 / 1$ (fase experimental) & $61 \%$ & $39 \%$ \\
$1990 / 2^{*}$ & $61 \%$ & $39 \%$ \\
$1991 / 1^{*}$ & $80 \%$ & $20 \%$ \\
$1989 / 1 * *$ & $31,8 \%$ & $63,6 \%$ \\
\hline
\end{tabular}

* Período em que o Projeto de Ensino já estava oficializado.

* Período em que a Prática de Ensino era realizada segundo os moldes "tradicionais".
QUADRO 3 - RESULTADO DA QUESTÃO 2 DO INSTRUMENTO: "AVALIAÇÃO FINAL DA DISCIPLINA 1 EST 228"

Questão 2: Como você classificaria a contribuição desta disciplina para a sua formação profissional?

( ) ótima ( ) boa ( ) regular ( ) fraca

\begin{tabular}{lrrr}
\hline & Ótima & Boa & Regular Fraca \\
\hline $1989 / 2$ (fase experimental) & $\mathbf{6 5 \%}$ & $35 \%$ & \\
$1990 / 1$ (fase experimental) & $\mathbf{5 5 \%}$ & $\mathbf{4 5 \%}$ & \\
$1990 / 2^{*}$ & $\mathbf{5 0 \%}$ & $\mathbf{4 4 , 5 \%}$ & $4 \%$ \\
$1991 / 1^{*}$ & $\mathbf{8 0 \%}$ & $\mathbf{2 0 \%}$ & \\
$\mathbf{1 9 8 9 / 1 ^ { * }}$ & $22,7 \%$ & $\mathbf{7 0} \%$ & $14 \%$ \\
\hline
\end{tabular}

* Período em que o Projeto de Ensino já estava oficializado.

** Período em que a Prática de Ensino era realizada segundo os moldes "tradicionais".

\section{QUADRO 4 - RESULTADO DAS QUESTÕES DE 01 E 07 DO INSTRUMENTO: "AVALIAÇÃO DA EDUCAÇAO CONTINUADA DO PROFES. SOR"}

Questões 01 e 07:

01. Você classificaria a qualidade do curso do qual participou:

$($ ) ótima ( ) boa ( ) regular ( ) fraca

07. Com relação aos objetivos estabelecidos para este curso, coloque na frente de cada um, o conceito que meIhor o classifica quanto ao seu cumprimento: ótimo, bom. regular, fraco.

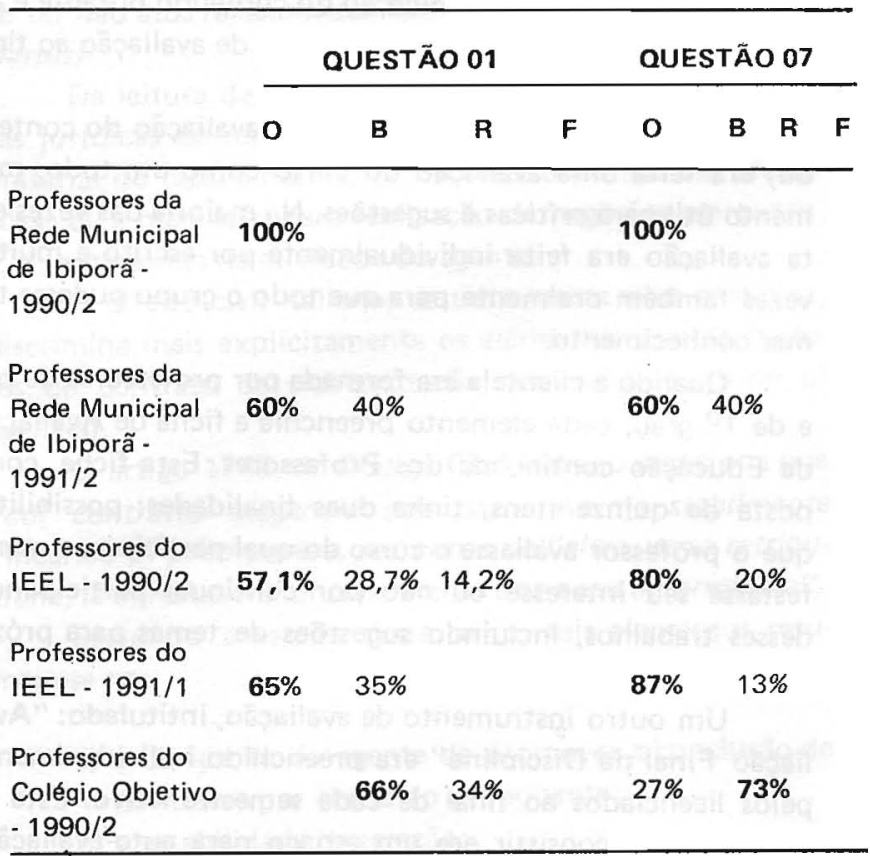


QUADRO 5 - RESULTADO DAS QUESTOES 10 E 11 DO INSTRUMENTO: "AVALIAÇÃO DA EDUCAÇÃO CONTINUADA DO PROFESSOR"

Questões 10 e 11 :

10. Como você avalia a atuação da equipe que coordenou o curso?

11. Você tem interesse em continuar participando destes cursos?

\begin{tabular}{|c|c|c|c|c|c|c|}
\hline & \multicolumn{3}{|c|}{ QUESTÃO 10} & \multicolumn{3}{|c|}{ QUESTAO 11} \\
\hline & 0 & B & $\mathbf{R}$ & $\mathbf{F}$ & $\operatorname{sim}$ & NÃO \\
\hline \multicolumn{7}{|l|}{ Professores da Rede } \\
\hline $\begin{array}{l}\text { Municipal de Ibiporã } \\
\text { 1990/2 }\end{array}$ & $100 \%$ & & & & $100 \%$ & \\
\hline \multicolumn{7}{|l|}{ Professores da Rede } \\
\hline $\begin{array}{l}\text { Münicipal de Ibiporã̃ } \\
1991 / 1\end{array}$ & $100 \%$ & & & & $100 \%$ & \\
\hline \multicolumn{7}{|l|}{ Professores do IEEI. } \\
\hline $1990 / 2$ & $57.1 \%$ & $28,7 \%$ & $14,2 \%$ & & $100 \%$ & \\
\hline \multicolumn{7}{|l|}{ Professores do IEEL } \\
\hline $1991 / 1$ & $82 \%$ & $18 \%$ & & & $100 \%$ & \\
\hline \multicolumn{7}{|l|}{ Professores do } \\
\hline $\begin{array}{l}\text { Colégio Objetivo } \\
1990 / 2\end{array}$ & & $100 \%$ & & & $100 \%$ & \\
\hline
\end{tabular}

\section{4 - DISCUSSÃO E CONCLUSÃO}

A preocupação com a questão da Licenciatura, em especial da Psicologia, tem merecido maior atenção na década de oitenta.

Comissão de Ensino CRP - Sindicato $\left({ }^{9}\right)$, Carvalho e Vianna (1) e Balzan e Paoli (5), entre outros autores, apresentam discussões em torno da problemática da Licenciatura. Essas discussões são evidentemente relevantes e voltadas para questões tais como: análise crítica das Licenciaturas no Brasil; o papel destas no âmbito da educação nacional; a preocupação com o currículo e o conteúdo programático dos cursos de Licenciatura; o apontamento da necessidade de melhoria da qualidade de ensino do educador.

O presente trabalho procura também oferecer contribuições para o enriquecimento da Licenciatura, buscando repensar e reformular mais especificamente a parte prática da mesma, ou seja, o estágio propriamente dito.

De acordo com os Quadros 2 e 3 é possível constatar que, nos quatro semestres em que se seguia a estratégia de Cursos-evento-extensão, a experiência em Prática de Ensino (Questão 1) e a contribuição da disciplina para a formação profissional dos licenciandos (Questão 2) foram classificados por estes como sendo ótimas ou boas, tendo incidida a porcentagem maior no conceito ótimo.

Em contrapartida, quando da realização do estágio de Prática de Ensino segundo os moldes tradicionais (cf. Qua. dro 2 e 3) a avaliação dos licenciandos se concentrou mais acentuadamente no conceito Bom.

Estes dois quadros permitem constatar que, segundo os licenciandos, a nova estratégia de estágio é considerada como sendo uma experiência mais enriquecedora e oferece maior contribuição para a formação profissional que a forma "tradicional" de realização da Prática de Ensino em Psicologia.

O Quadro $n^{0} 1$ nos permite constatar que esta estratégia de trabalho tem encontrado receptividade junto às Instituições da cidade de Londrina, incluindo também cidades vizinhas (Ibiporã e Cambé).;

É oportuno esclarecer que no caso do Colégio Estadual Maria do Rosário Castaldi (conforme quadro 1) e do Colégio Objetivo (conforme quadros 4 e 5 ) não foi possível dar continuidade aos cursos no primeiro semestre de 1991 devido a dificuldade de arranjo de horário entre licenciandos e clientela, uma vez que o horário em que o curso é ministrado fica em função das possibilidades dessa última.

Os Quadros 4 e 5 nos permitem concluir que os cursos ministrados para professores, segundo esses, foram eficazes. Tendo em vista que é geral o interesse destes professores por continuar participando de cursos (cf. questão 11 , quadro 5) acredita-se que foi possível alcançar um dos principais objetivos do curso ministrado para professores, qual seja: despertá-los para a necessidade e importancia do seu compromisso com sua "educação continuada" conforme comenta Celani (11).

Três dados contribuem de forma especial para uma avaliação positiva desta nova proposta de trabalho.

O primeiro diz respeito d̀s várias possibilidades de realização do Curso-evento-extensão intitulado: "Treinamento em Habilidades Técnicas de Ensino-Micro-Ensino", que consiste em um curso prático para turmas de cinco alunos. No segundo semestre de 1990, duas licenciandas, tendo participado do Treinamento em Habilidades Técnicas de Ensino ao cursar a disciplina Metodologia e Prática de Ensino em Psicologia I, propuseram a realização de tal treinamento para as alunas do Magistério ( $2^{\circ}$ grau) do Colégio Mãe de Deus, e a proposta foi acejta tanto pela administração da escola como por alunas que se mostraram interessadas.

Neste período foram formados três grupos de alunos do magistério, havendo cinco em cada grupo, onde em cada um havia uma licencianda coordenando o treinamento.

No semestre seguinte (1990/2) o curso foi ministrado para dois novos grupos, no mesmo colégio.

Conforme solicitação de uma professora-irmã que acompanhava indiretamente estes trabalhos, o mesmo curso passou a ser ministrado, no semestre seguinte, no Colégio de Enfermagem Mater Ter Admirabilis (Irmandade Santa Casa de Londrina) para docentes do curso profissionalizante desta Instituição. A professora que fez a solicitação também participou neste momento, como aluna do curso.

O segundo dado que contribui para a avaliação positiva desta nova proposta de trabalho refere-se aos cursos ministrados para professores da Rede Municipal de Ensino de Ibiporã. Há quatro semestres consecutivos os cursos vem sendo realizados, dividindo-se a clientela em dois grupos, uma vez que a média é de 23 a 32 professores por semestre. 
Também já se deu início ao planejamento para o quinto semestre do curso com essa clientela.

É válido esclarecer que tal trabalho foi desenvolvido em função da solicitação feita pelo prefeito de Ibiporã, em 1989, em reunião com representantes de vários setores da UEL, onde o mesmo solicitava ajuda desta Instituição na efetivação de vários projetos. Nessa reunião, a pessoa responsável pelo setor de Educação esclareceu sobre a necessidade de reciclagem dos professores da rede e solicitou a colaboração específica do Departamento de Psicologia.

Uma solicitação feita pela Coordenadora do Magistério do IEEL (Instituto Estadual de Educação de Londrina) à professora responsável por Prática de Ensino em Psicologia consiste no terceiro dado significativo de avaliação positiva da proposta de curso-evento-extensão. Em uma reunião ocorrida em agosto de 1991 para se planejar a continuidade de cursos nesta Instituição - que já vem ocorrendo desde 1990/2 conforme Quadro 1 - a Coordenadora expõe sobre seu interesse em contar com a colaboração dos estagiários de Prática de Ensino em Psicologia para complementar a formação dos alunos do curso de Magistério. A Coordenadora esclareceu que diante da nova Proposta Curricular da Habilitação Magistério que deverá entrar em vigor em 1992 - onde ficará diminuído o número da carga horária da disciplina Psicologia, uma vez que passará a ser ministrada "apenas" no $1^{0}$ ano do Magistério - será inviável para o professor dar conta de toda programação já proposta para a disciplina intitulada Psicologia da Educação. Então, os cursos-evento-extensão poderiam ajudar, segundo opinião da referida Coordenadora, para que, em horários extras, as alu- nas do magistério possam apreender todo o conteúdo de Psicologia considerando essencial à sua formação profissional.

É possivel constatar que as justificativas que nortearam a criação desta nova estratégia de Prática de Ensino se fazem valer até o presente momento, destacando-se em especial a seguinte justificativa: "a necessidade e utilidade da experiência para o profissional da área de Psicologia, em programar, ministrar e avaliar um curso, seja qual for sua área de atuação".

Assim sendo, esta forma de trabalho é mais útil ao licenciando e apresenta maior validade social que os estágios desenvolvidos anteriormente dentro das salas de aula de Psicologia, obedecendo a programação pré-determinada. Nessa última situação, quer o licenciando esteja lá ou não, as aulas vão acontecer pois já existe um professor responsável pelas mesmas. Enquanto isso, há toda uma comunidade, composta por professores, crianças, adolescentes e pessoas de forma geral, que podem usufruir dos conhecimentos de Psicologia para compreender-se melhor, sentir-se mais saudável e aplicar enfim os conhecimentos, seja no trabalho ou na vida pessoal.

Os fatores que justificam a validade desta estratégia são: a contribuição para a melhoria do curso de graduação em Psicologia, especialmente da Licenciatura; o fato de desenvolver-se num contexto onde considera-se a necessidade da comunidade e principalmente, a priorização da democratização do saber.

Finalmente é possível concluir que os objetivos pro. postos foram alcançados.

\section{ABSTRACT}

The objective of this work was to propose a new alternative for the Teaching Practicum in Psychology which could provide better experiences for the licentiate student in the Educational field in terms of quality and in regards to the community needs. The methodology of this work consisted of planning, accomplishing and evaluating the extension courses and events of 20 or 30 hours taught by the licentiate students to Primary and Secondary school students, teachers of preschool and primary school, nursery employees and the community in general. The results showed that in a significantly higher proportion the licentiate students considered, the experience in Teachining Practicum and the contribution of it to his/her professional career to be excellent. The clientele, as a whole, evaluated positively the quality of the courses and the range of the proposed objectives. It was concluded that the nev alternative has brought new improvement to the Teaching Practicum, providing an integration of students of Higher Education with the primary and secondary teaching and the community in general, in favor of the knowledge democratization.

\section{KEY-WORDS: Licentiate in Psychology; Teaching Practicum; Training in Psichology; Extension courses and events}

\section{REFERÊNCIAS BIBLIOGRÁFICAS}

1. Carvalho, Ana Maria Pessoa de \& VIANNA, Deise Miranda. A quem cabe a licenciatura. Ciênc. e Cult., São Paulo, 40 (2): 146 , fev. 1988.

2. GATTI, Bernadete. A formação de professor de $1^{\circ} \mathrm{Grau.} \mathrm{(São}$ Paulo: s.n.), 1987. Texto mimeo.

3. MELLO, Guimar Namo de; MAIA, Eny Marina; BRITTO, Vera Maria Vedovelho. As atuais condições do professor de $1^{\circ}$ grau : algumas reflexões e hipóteses de investigação. Cad. Pesq., São Paulo, (45): 71-78, maio, 1983.

4. BOYTEUX, Bayard. Depoimento: Bayard Boyteux. Ande, v. 4, n. 7,19

5. BALZAN, Newton César; PAOLI, Niuvenius. Licenciaturas - 0 discurso $\theta$ a realidade. Cienc. e Cult., Săo Paulo, $40(2)$ : p. 147-150, fev., 1988. 
6. BRAGA, Mauro Mendes. A licenciatura no Brasil: um breve histórico sobre o período de 1973-1987. Cienc. e Cult. Såo Paulo, 40(2): p. 151-157, fov. 1988.

7. PARRA, Nélio. Curso de licenciatura: uma proposta de reforma. R. Fac. Educ., S\&o Paulo, 10(2): p. 191-197, jul./dez., 1984.

8. COORDENADORIA DE ESTUDOS E NORMAS PEDAGÓgICAS. Conselho Regional de Psicologia. Sindicato. Sugestões de Conteúdo programático para a disciplina Psicologia no $2^{\circ}$ grau. Psicologia no Ensino de $2^{\circ}$ Grau: uma proposta emancipadora. Sao Paulo: Edicon, 1986. Cap. 1, p.1-9.

9. COMISSÃo de ENSINO. Conselho Regional de Psicologia. Sindicato. $O$ ensino de psicologia no $2^{\circ}$ grau: problemas e perspectivas. In; Conselho Regional de Psicologia, $6^{\text {a }}$ Regiăo (Så Paulo). Psicologia no Ensino de $2^{\circ}$ Grau: uma proposta emancipadora. São Paulo: Edicon; 1986. Cap.2, p.10-15.
10. MEZZAROBA, Solange Maria Beggiato. Habilitação profissional de magistério - curso de $2^{\circ}$ grau. A formaçó do professor alfabetizador. Săo Paulo: PUC, 1987. Dissertação (Mestrado em Psicologia da Educacão) - Pontifícia Universidade Católica de Såo Paulo, 1987.

11. CELANI, Maria Antonieta Alba. A oducação continuada do professor. Cienc. e Cult., S\&o Paulo, 40(2): p. 158-163, fev. 1988

12. CAMPOS, Terezinha Calil Padis. Ensino de Psicologia pare crianças e adolescentes. Rev. Brasil. de Pesq. em Psicol. Såo Caetano do Sul, $1(0)$ : p. 31-32, 1988.

13. GNERRE, Maurício. Linguagem, escrita e poder. Såo Paulo: Martins Fontes, 1985.

14. RONCA, Antonio Carlos \& ESCOBAR, Virgínia Ferreira. Técnicas pedagógicas: domesticação ou desafio à participaçå? 3. ed. Petrópolis: Vozes, 1984. 113p.

\title{
UMA ABORDAGEM ORGANIZACIONAL DO STRESS: RELATO DE UMA PESOUISA
}

\author{
THEREZINHA SOARES SANTOSa \\ YARA LUCIA MAZZIATTI BULGACOV ${ }^{a}$ \\ ADRIANA CRISTINE DIAS ${ }^{b}$ \\ MARIA JULIA SCICHITANO \\ DNAIR ROSELEM CASARINIb \\ ELIZABETE H. TAKIZAVA \\ SANDRA CRISTINA M. CAYRES ${ }^{b}$
}

\section{RESUMO}

Este artigo tem como objetivo relatar uma experiência junto a uma organização estatal, e numa perspectiva organizacional, identificar fatores de stress, variáveis a ela relacionadas, bem como seus sintomas. A população alvo consistiu em 28 sujeitos, pesquisadores de nível de escolaridade superior e de classe econômica média alta. Fundamentada em uma visão interacionista do stress (Lazarus, 1966 e Sells, 1970) a investigação foi delineada a partir do equacionamento de tres niveis de variações: a) variáveis ambientais (fatores de trabalho e organizacionais); b) variáveis individuais (avaliação cognitiva e traço de ansiedade); c) sintomas a nível psicológico, comportamental e fisiológico. Para a coleta de dados foram utilizados os seguintes instrumentos: I.D.A.T.E. (Inventário de Auto-Avaliação para Ansiedade de Traço e Espaçol; Entrevista semi-estruturada; Pfister (Teste projetivo das pirâmides coloridas); Escala de Frequência de Sintomas. Os resultados permitiram a identificação dos seguintes dados: frequência de fatores estressores; frequência de sintomas e de niveis de ansiedade dos sujeitos e do grupo. O tratamento dos dados consistiu, a partir dos resultados parciais dos instrumentos aplicados, de uma análise estatística que possibilitou a distribulça da população pesquisada em quatro zonas, a saber: zona de risco, zona crítica, zona de normalidade e zona de baixo risco. Os resultados foram devolvidos a população alvo, momento este em que se trabalhou com os conceitos de "Chamada Cognitiva" (Couto, 1987) e Estilo de Vida A Friedman \& Roseman apud Couto, 1987. Apontou-se, a partir de então, duas situações: as passíveis de mudança, que permitiram trabalhar respectivamente com indicações de estratégias de mudanças organizacionais, e com a questão da aceitação adequada do imponderável.

PALAVRAS-CHAVE: Fatores de stress; abordagem organizacional do stress; estressores no trabalho.

\section{1 - INTRODUÇÃO}

Poucos temas têm recebido tanta atenção ultimamente, como o "stress". Dentro da psicologia, numa tentativa de se dar um "status científico" para o termo, a meta tem sido clarificar a natureza do que se tem demonstrado ser um vago e heurístico constructo (Hobfoll, 1989). Além desse interesse teórico, se constata uma demanda cada vez maior,

a - Departamento de Psicologia Social e Institucional/CCB - Universidade Estadual de Londrina

b - Estagiárias de Psicologia do Trabalho do Departamento de Psicologia Social e Institucional/CCB - Universidade Estadual de Londrina 